\title{
Falsafah Pragmatisme John Dewey dan Pembelajaran Sepanjang Hayat dalam 'Muallaf'
}

\author{
John Dewey's Pragmatism and Lifelong Learning as in 'Muallaf'
}

\author{
SITI ARINAH TUKIRAN*, AHMAD SUNAWARI LONG \& BADRUL REDZUAN ABU HASSAN ${ }^{1}$
}

\begin{abstract}
The philosophy of pragmatism was initiated in America in the last 19th century. It reflected the philosophy the Americans and it widely applied in the domain of education. One of the prolific pragmatism figures is John Dewey who was popular with pragmatism in the version of instrumentalism. He was also very popular as an educator who propagated experience as an effective basis to gain knowledge. To explain Dewey's thought, Muallaf film which was directed by Yasmin Ahmad in 2008, has been chosen due to its lucid depiction of education in different context. Therefore, this article will discuss the meeting point between Dewey's pragmatism and the concept of education in the Yasmin's perspective through two selected sequences which specifically featured the concept of experienced based education. Though there are not many formal educational scenes in the film, the strength of the scenes in the selected frames emphasized the importance of education in society. This study is qualitative research design using semiotic analysis of verbal and non-verbal in the Muallaf and library research to retrieval of data or materials needed to complete the study came from the library, including books, dictionaries, journals, documents, and so on. The result of this study has concluded that Yasmin Ahmad has clearly featured the concept of experience as a process of the lifelong learning which is congruent with Dewey's pragmatism's thought.
\end{abstract}

Keywords: John Dewey, liefelong learning, Muallaf, pragmatism, Yasmin Ahmad

Secara amnya, pragmatism atau pragmatisme berasal daripada bahasa Latin "pragmaticus" dan bahasa Yunani "pragmatikos" yang bermaksud perbuatan atau tindakan (Ormerod 2006). Manakala dari aspek teknikal, sebagaimana yang dijelaskan oleh A Dictionary of Philosophical Terms and Names (2011), pragmatisme adalah teori yang menekankan kesan-kesan praktikal suatu idea dan fungsinya terhadap tindakan (Anastasia 2015). Falsafah Pragmatisme mula dirintis di Amerika pada akhir abad ke-19. Falsafah ini mencerminkan pandangan hidup penduduk Amerika termasuklah bidang pendidikan. Ia dilihat menyatukan pelbagai percanggahan pada ketika itu, contohnya percanggahan di antara sains dengan agama dan intuisi berbanding empirisme (Scheffler 1974). Charles S. Peirce (1839-1942), William James (1842-1910) dan John Dewey (1859-1952) merupakan antara tokoh

\footnotetext{
${ }^{1}$ Siti Arinah Tukiran*(corresponding author), M.A. student at the Centre for Akidah and Global Peace, Universiti Kebangsaan Malaysia, 43600 BANGI, Selangor, Malaysia, email: intanarin78@gmail.com; Ahmad Sunawari Long, Ph.D., assoc. prof. at the Centre for Akidah and Global Peace, Universiti Kebangsaan Malaysia, 43600 BANGI, Selangor, Malaysia, email: aslong@ukm.edu.my; Badrul Redzuan Abu Hassan. M.A., senior lecturer at School of Media \& Communication Studies Faculty of Social Sciences \& Humanities, Universiti Kebangsaan Malaysia 43600, BANGI, Selangor, Malaysia, email: brah@ukm.edu.my.
}

https://doi.org/10.24035/ijit.15.2019.012 
pemikir falsafah ini. Di antara ketiga-tiga tokoh pemikir pragmatisme awal, Dewey sering dikaitkan dengan orang yang mempunyai kepakaran mendalam dalam bidang falsafah, psikologi dan pendidikan di Amerika Syarikat (Field 2007; Theobald 2009). Dewey dikatakan sebagai bayangan kepada Peirce melalui pemikirannya berkaitan metode eksperimental dan dia menjadi bayangan kepada James jika dilihat dari pemikirannya yang memfokuskan kepada akibat daripada sesuatu pemikiran. Di tangan Dewey, pragmatisme menjadi kaedah untuk berfikir dan bertindak dengan cara yang kreatif dan berwawasan (Maddux \& Donnett 2015).

\section{Penyataan Masalah}

Sepintas lalu, pemikiran yang dibawa oleh tokoh falsafah pragmatisme khususnya John Dewey sering dikonotasikan dengan pandangan negatif khususnya para agamawan. Namun tidak kurang hebatnya, terdapat pandangan yang melihat pemikiran fahaman falsafah ini membawa kepada kesan positif seperti dalam kajian Omar et al. (2014) dan Joanna (1996). Malah jika ditelusuri sistem pendidikan negara, idea falsafah ini telah dijadikan sebagai asas kepada pembentukan Falsafah Pendidikan Kebangsaan (FPK). Sudah pasti akan ditemui idea-idea atau pemikirannya yang telah diambil untuk menambahbaik sistem pendidikan di Malaysia. Sehubungan dengan itu, makalah ini akan mengungkap persoalan tentang pemikiran falsafah pragmatisme John Dewey dalam pendidikan khususnya pembelajaran sepanjang hayat. Pemikiran tersebut berkait rapat dengan pengalaman sebagai guru yang akan diungkap menerusi filem Muallaf arahan Yasmin Ahmad. Penulis memfokuskan kepada pengalaman kerana pengalaman merupakan proses timbal balik dan kerap mempengaruhi sesorang individu dengan persekitarannya.

\section{Metodologi}

Makalah ini dihasilkan daripada kajian penyelidikan asas dengan reka bentuk kaedah kualitatif . Kaedah ini diaplikasikan bagi menganalisis data dari dua sumber iaitu sumber utama dari filem Muallaf yang durasi lapan puluh tujuh minit dengan menggunakan analisis semiotik terhadap elemen verbal dan elemen bukan verbal. Sementara, sumber kedua pula diperolehi daripada penelitian kepustakaan seperti buku, jurnal, akhbar, tesis, makalah, internet dan sebagainya.

\section{Hasil Kajian dan Perbincangan}

John Dewey dilahirkan di Burlington, Vermont pada tahun 1859. Setelah menamatkan pendidikan di Universiti John Hopkins, beliau bertugas di Unversiti Minnesota selama sepuluh tahun dan kemudian mengetuai Jabatan Falsafah, Psikologi dan Pedagogi di Universiti Chicago pada tahun 1894-1904 (Stroh 1968). Ketika di sini, Dewey menubuhkan Sekolah Dewey, namun kemudiannya terpaksa melepaskan jawatannya kerana berlaku kontroversi. Setelah itu beliau bertugas di Universiti Columbia pada tahun 1904-1929. Antara karya Dewey yang dianggap penting adalah Freedom and Cultural, Art and Experience, The Quest of Certainty Human Nature and Conduct (1922), Experience and Nature (1958), dan yang paling fenomenal Democracy and Education (1964). Dewey meninggal dunia pada tahun 1952 di New York ketika berusia 93 tahun (Margolis 2000).

Jika diteliti, dasar pemikiran falsafah pragmatisme John Dewey, berakar umbi daripada pemikiran beberapa tokoh terdahulu. Selain daripada Peirce dan James yang telah dinyatakan sebelum ini, pragmatisme Dewey turut dipengaruhi oleh pemikiran Hegel. Pemikiran tersebut memfokuskan peranan sesebuah institusi untuk mengawal manusia dan tiada usaha individu (Dewey 1938). Begitu juga dengan pengaruh Darwin yang percaya inteligent sebagai alat dalam struggle for 
survival iaitu alat yang berfungsi ketika manusia menghadapi rintangan. Gabungan konsep pemikiran Hegel dan Darwin yang menggangap sejarah selalu berubah dan nilai semua benda terbatas dalam konteks sejarah tempat asal mereka muncul turut mempengaruhi Dewey (Dewey 1964). Misalnya, pemikiran tentang teori ilmu yang tidak mementingkan sumber pengetahuan tetapi mengutamakan tentang natijahnya dipengaruhi oleh James. Berdasarkan teori ini, sesuatu idea akan dikategorikan bermanfaat sekiranya dianggap bernilai dalam kehidupan. Teori ini turut dilihat mempertikaikan dualisme di antara pemikiran dengan tindakan. Oleh kerana itu, Dewey tidak mengasingkan antara pemikiran dengan tindakan sebagaimana aliran-aliran sebelumnya yang memisahkan antara pemikiran dengan tindakan (Dewey 1938). Bagi Dewey, pemikiran tidak dianggap sebagai himpunan deria atau artifact 'kesedaran' ataupun manifestasi minda mutlak. Pemikiran merupakan instrumen fungsi yang diperluaskan untuk melayani kepentingan kemandiran dan kebajikan manusia. Malahan, menerusi teori ilmu ini juga, sesuatu pemikiran hendaklah diuji melalui tindakan sekiranya hendak diterima sebagai ilmu (Nagendralingan Ratnavadivel 2007).

Sebagai tambahan, versi pragmatisme Dewey turut dikenali sebagai Instrumentalisme (Thayer 1981). Versi ini melihat pengalaman sebagai asas yang membawa maksud suatu usaha untuk menyusun suatu teori yang logik dan tepat dari konsep-konsep, pertimbangan-pertimbangan, penyimpulan-penyimpulan dalam pelbagai bentuk dengan cara menyelidik bagaimana fikiran berfungsi berdasarkan pengalaman yang berkaitan kesan-kesan pada masa depan (Dewey 1956). Dengan itu, aktiviti berfikir tidak dilihat sekadar aktiviti kognitif tetapi meliputi semua kehendakkehendak yang wujud dalam diri ketika berhadapan dengan persekitarannya. Sekaligus Dewey melihat 'pengalaman' sebagai kunci dalam menilai sesuatu (Dewey 1938).

\section{Pengalaman Sebagai Asas Pemikiran Pragmatisme Dewey}

Pengalaman adalah jaringan kompleks dari interaksi manusia dan persekitaran (Dewey 1958). Untuk memudahkan proses memahami konsep pengalaman, Omar (2014) memetik kata Boisvert (1995) yang menjelaskan bahawa pengalaman menurut terma Dewey dalam Experience and Nature (1958) dan Art as Experience (1934) merupakan aktiviti manusia yang tidak boleh dipisahkan daripada minat manusia ataupun aktiviti penemuan. Pengalaman bukan seperti yang difahami oleh golongan emperis British di abad ke-17 dan 18 (Dewey 1958), yang mempercayai pengalaman hanyalah sebagai anggapan. Maka, sudah tentu, pengalaman yang dilihat secara konvensional sebagai suatu yang misteri (Talisse 2000). Penjelasan tersebut dinyatakan melalui petikan berikut:

Experience is a central term in the Deweyan vocabulary. Indeed, it figures prominently in the titles Dewey chose for two of his most important works, Experience and Nature, and Art as Experience ... Experiencing is a fully human activity. It can be separated neither from human interests, nor from active experimentation ... experience [is] not to be understood in the empiricist sense of simply receiving impressions (Boisvert 1995).

Dewey berpendapat bahawa pengalaman merupakan kombinasi pelik yang terdiri daripada dua unsur iaitu aktif dan pasif. Dari sisi aktif pengalaman dianggap sebagai percubaan atau eksperimen sementara dari sisi pasif, pengalaman merupakan sesuatu yang sedang berlangsung. Dewey menggangap pengalaman sebagai kombinasi pelik kerana individu yang mengalaminya akan bertindak dan apabila bertindak individu tersebut akan merasai kesannya. Hubungan antara dua fasa pengalaman ini (perbuatan dan tindakbalas) dapat menentukan nilai dan hasil daripada pengalaman (Dewey 1958). 
Dewey turut menjelaskan dua prinsip asas untuk memahami pengalaman (Keitges 2015). Pertama, prinsip kesinambungan pengalaman (continuity of experience/experiential continuum). Prinsip ini membawa maksud semua pengalaman lampau diambil untuk mengubah pengalaman pengalaman masa depan (Dewey 1938). Kedua, prinsip interaksi (transaksi). Prinsip ini menentukan hak yang sama terhadap keadaan dalaman dan luaran individu. Situasi luaran melibatkan seluruh yang ada di luar diri individu misalnya orang, benda, subjek dan sebagainya sementara situasi dalaman pula adalah semua yang ada dalam diri individu. Interaksi antara objektif dan internal akan mewujudkan "situasi" iaitu kehidupan individu dalam dunianya (Dewey 1938). Sekaligus menggambarkan realiti ialah interaksi antara manusia dengan alam sekelilingnya. Kedua-dua prinsip ini tidak boleh diasingkan kerana berfungsi untuk membezakan antara pengalaman yang bermanfaat dan yang tidak bermanfaat (Dewey 1938). Dengan kata lain, ianya merupakan transaksi dua hala yang melibatkan manusia bertindak balas ke atas alam sekelilingnya dan begitulah sebaliknya. Kedua-dua prinsip inilah membolehkan seseorang individu itu menyelesaikan masalah yang dihadapinya.

\section{Pendidikan Menurut Pandangan Dewey}

Berdasarkan kepada beberapa karyanya yang terpilih terutama tulisannya yang terkenal iaitu Democracy and Education: An Introduction to the Philosophy of Education (1964) dan The School and Society (1920), pendidikan difahami secara terminologi sebagai the process of forming fundamental dispositions, intellectual and emotional forwards nature and fellow men iaitu pendidikan merupakan proses pembentukan asas pembawaan, intelektual dan emosi terhadap persekitaran dan manusia (Dewey 1964). Dewey turut menghuraikan bahawa pendidikan merupakan usaha menyusun pengetahuan untuk membantu manusia meningkatkan lagi pengetahuan yang dimiliki, iaitu pengetahuan yang membawa kepada kehidupan lebih selamat, bermanfaat dan bertambah tinggi lagi darjat pengetahuannya (Abdul Munir 2010).

Namun bagi penulis, kemungkinan penyataan yang paling sesuai untuk menghuraikan pendidikan menurut pandangan John Dewey dalam penulisan ini, dapat diteliti daripada ungkapan . .. process of renewal of the meaning of experience..., dengan penyampaian sama ada melalui interaksi dengan orang yang lebih tua atau melalui institusi pendidikan formal (Sharifah Alwiah 1984). Barangkali ungkapan yang paling mudah untuk menjelaskannya adalah dengan memahami bahawa belajar melalui amalan learning by doing atau pendidikan yang terhasil setelah melakukan sesuatu perbuatan. Teori ini merupakan suatu kaedah yang mengutamakan setiap perbuatan yang dilakukan oleh individu akan menghasilkan pengalaman yang baharu (Dewey 1938; Abdul Munir 2010). Pengetahuan juga dilihat sebagai suatu fenomena sementara yang perlu diselidik dan diperbaharui mengikut situasi. Penggunaan pengetahuan lebih diutamakan berbanding pencarian kebenaran. Oleh kerana itu, proses eksperimen yang berbentuk saintifik bagi mencari penyelesaian masalah secara rasional amat diperlukan dalam pendidikan (Mohamed Nor Che'Nor 1990).

Dengan pemahaman ini juga, pengalaman biasa dalam dunia sehari-harian ialah satu-satunya realiti yang sentiasa ada pada manusia dan yang diperlukannya serta terhasil dari interaksi di antara manusia dengan sekeliling (Musa 1973). Interaksi tersebut seterusnya akan membawa perubahan kepada manusia ataupun persekitarannya (Mohamed Nor Che'Nor 1990). Maka, tugas sekolah bukan untuk merubah masyarakat tetapi lebih bertujuan untuk mengenalkan murid-murid kepada masyarakat yang sebenarnya berubah (Dewey 1920; Dewey 1938; Gutek 1988). Sekolah juga bukan sebagai sebuah tempat untuk murid membuat persediaan untuk terus hidup tetapi merupakan tempat bagi murid untuk hidup dalam masyarakat yang lebih kecil daripada masyarakat yang lebih besar di luar sekolah (Dewey 1938). Dengan makna lain, sekolah bukan hanya tempat untuk mengisi pelbagai ilmu dan pengetahuan ke dalam otak murid-murid semata-mata tetapi lebih dari itu kerana 
ia merupakan tempat murid-murid hidup secara bermasyarakat dan juga dapat menyediakan penghidupan yang seimbang dengan perkembangan umur dan bakat murid-murid (Dewey 1920). Oleh kerana itu, Dewey mengkritik sekolah yang mengabaikan minat dan pengalaman murid mengasingkan murid daripada realiti serta pengujian mentaksir pembelajaran murid serta membezakan murid berdasarkan kebolehan yang diandaikan. Bagi Dewey, guru perlu membimbing murid membuat perkaitan antara minat mereka dan perkembangan intelek yang berterusan serta pengalaman berunsur pendidikan (Nagendralingan 2007).

Selanjutnya, dalam mendasari pemikiran pendidikannya, pengalaman sebagai senjata utama dalam merealisasikan pendidikan (Gibson 2016), Dewey turut berjaya mengilhamkan idea pembelajaran sepanjang hayat. Bagi Dewey, pendidikan tidak hanya meliputi atau melibatkan pembinaan pengalaman dalam kehidupan murid-murid di sekolah tetapi berlangsung secara berterusan sepanjang kehidupan manusia (Peterson 1987). Maka, guru perlu menyedari murid yang datang ke sekolah bukan hadir dengan 'sifar' pengalaman tetapi hadir dengan pelbagai pengalaman. Pengalaman inilah yang perlu difahami oleh guru agar proses pembelajaran dan pembelajaran dapat disampaikan dengan baik (Joanna 1996). Lalu, menjadi tugas utama sekolah untuk menyediakan situasi yang membolehkan kesinambungan pendidikan selepas berakhirnya persekolahan dengan menghasilkan produk terbaik yang membolehkan setiap murid memperolehi peluang merasai pembelajaran sepanjang hayatnya.

\section{Pembelajaran Sepanjang Hayat (PSH) di Malaysia}

Menulusuri sistem pendidikan di Malaysia ketika filem Muallaf ini dihasilkan, kita akan temui usaha kerajaan Malaysia mengambil tindakan proaktif mengubal dasar di mana PSH agar menjadi teras utama dalam perancangan pembangunan negara. Rangka Rancangan Jangka Panjang Ketiga (RRJP3) bagi tempoh 2001-2010 dan Dasar Wawasan Negara merupakan rangka pembangunan negara jangka panjang bagi menghadapi cabaran globalisasi, liberalisasi ekonomi dan persekitaran ekonomi berasaskan pengetahuan. Usaha tersebut dilakukan dengan menyediakan kemudahan untuk menguasai ilmu pengetahuan dan meningkatkan kemahiran walaupun selepas tamat pendidikan dan latihan formal. Pelan Pembagunan Pendidikan Malaysia (PIPP) 2006-2010 turut membudayakan pembelajaran sepanjang hayat dengan menggariskan enam teras iaitu membangunkan modal insan, memperkasakan sekolah kebangsaan, merapatkan jurang pendidikan, memartabatkan keguruan dan melonjakkan kecemerlangan institusi pendidikan. Dalam lain perkataan Kementerian Pelajaran Malaysia (KPM) menyediakan PIPP untuk menggariskan fokus, strategi utama, dan pelan pelaksanaan bagi menjadikan pendidikan negara relevan mengikut keperluan semasa dan masa hadapan. Jesteru itu, Yasmin melihat keadaan ini sebagai satu peluang untuk menanamkan kepentingan pendidikan dalam filem-filem arahannya dengan memfokuskan kepada pendekatan pembelajaran sepanjang hayat kepada masyarakat menerusi filem Muallaf.

\section{Muallaf Arahan Yasmin Ahmad}

Filem Muallaf dihasilkan oleh air tangan Allahyarhamah Yasmin Ahmad (7 Januari 1958 - 25 Julai 2009) pada 2008. Yasmin merupakan antara pembikin filem Malaysia yang menghasilkan filem yang memiliki keistimewaannya yang tersendiri. Muallaf merupakan filem kelima daripada enam buah filem yang telah dihasilkan oleh Yasmin, iaitu Rabun (2003), Sepet (2005), Gubra (2006), Mukhsin (2007), Muallaf (2008) dan Talentime (2009). Kehebatan filem Muallaf terbukti di festival filem dalam dan luar negara. Misalnya, filem ini telah merangkul beberapa anugerah antaranya, Festival Filem Antarabangsa Tokyo Ke-21 (21st Tokyo International Film Festival) (18-26 Okt 2008), Anugerah 
Khas Filem Terbaik Asia-Timur Tengah (Special Mention Best Asian-Middle Eastern Film) dan Anugerah Filem Terbaik dan Pengarah Terbaik filem dalam Anugerah Skrin 2010.

\section{Muallaf: Sinopsis dan Sub-Naratif}

Filem Muallaf berlatarbelakang naratif utama pengalaman kehidupan Brian, seorang yang sedang mencari agama setelah tidak mempercayai agama kerana peristiwa ditelanjangkan oleh bapanya di khalayak ramai. Pencarian kebenaran agama menemukan Brian dengan dua orang adik beradik iaitu Rohana dan Rohani. Perkenalan mereka bermula apabila Brian yang merupakan guru subjek Sejarah di sekolah menghantar muridnya, Rohana pulang ke rumah setelah dirotan oleh Puan Siva. Sepanjang perkenalan, mereka dilihat gemar mengkaji terjemahan Kitab al-Quran berbahasa Inggeris, menghayati dan mencuba untuk memahami ayat-ayat yang dipetik daripada kitab-kitab suci agama lain dan petikan-petikan lain berkaitan agama. Sub plot yang lain pula, memaparkan ragam harian manusia misalnya kisah Brother Anthony sebagai pengetua sekolah yang sentiasa prihatin dengan para guru dan anak-anak muridnya, kisah Puan Siva yang prejudis terhadap Rohana; kisah pelayan di kedai mamak yang menaruh perasaaan terhadap Rohani; kisah Tulip yang sanggup mempertahankan ibunya daripada dipukul oleh bapanya; kisah 'ustaz' yang mudah mesra dengan orang sekeliling dan kisah Puan Yap yang menyedari perubahan sikap Brian dari seorang yang kedekut kepada sebaliknya dan kebolehan yang ada dalam diri Rohana mengintepretasikan petikanpetikan berkaitan dengan agama. Kesemua sub naratif ini jelas mengangkat tema pengalaman yang akhirnya mendidik manusia menjadi 'seseorang' dalam masyarakat. Secara tidak langsung pendidikan sepanjang hayat terwacana di sebalik pengalaman yang dialami oleh watak-watak yang telah dilakar oleh Yasmin secara berhikmah dalam pergaulan sesama masyarakat.

\section{Analisis Teori Filem Muallaf}

Berikut merupakan dua bingkai yang telah dipilih oleh penulis bagi menjelaskan perincian perbahasan di anatara pandangan Yasmin dengan John Dewey terhadap pembelajaran sepanjang hayat menerusi filem Muallaf:

\section{Bingkai 1}

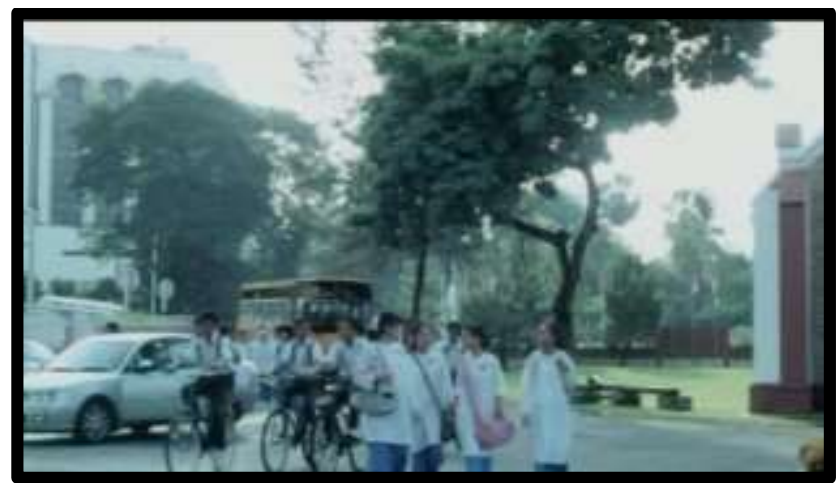

Bingkai 1 memaparkan sekumpulan pelajar terdiri daripada lelaki dan perempuan, muslim dan bukan muslim dan pelbagai lagi perbezaan lain yang mewakili masyarakat majmuk, baru sahaja tiba di bahagian pintu masuk sebuah kawasan sekolah. Mereka ini dipaparkan ada yang hadir ke sekolah dengan berkereta, ada yang menaiki bas, ada yang menaiki motor, berbasikal dan juga berjalan kaki. 
Mise en scene bingkai 1 ini memperlihatkan firasat Yasmin bahawa peluang pendidikan yang adil dan sama rata perlu diberikan kepada semua tanpa mengira status sosial mereka. Hasrat KPM ini bertujuan untuk membasmi murid yang tercicir daripada alam persekolahan akibat kemiskinan, di samping memberikan golongan ini akses pendidikan yang sama rata dalam menjana kecemerlangan negara. Sekaligus menggambarkan sekolah adalah permulaan proses pembelajaran sepanjang hayat iaitu manusia mula membina fleksibiliti dan inovasi dalam kehidupan menerusi sekolah. Tanpa disedari firasat Yasmin berjaya menyampaikan mesej bahawa sekolah sebagai institusi pendidikan yang formal perlu mengorak langkah lebih jauh untuk mempelbagaikan pendidikan agar dinikmati semua golongan.

Firasat Yasmin ini dilihat seiring dengan pandangan Dewey yang melihat pengalaman dialami oleh setiap individu secara berterusan. Pengalaman tersebut hanya akan terhasil apabila wujud interaksi di antara manusia dengan sekeliling sehari-harian. Hal ini kerana, pengalaman merupakan satu-satunya realiti yang sentiasa ada pada manusia dan yang diperlukannya. Maka bagi individu yang bergelar murid, sudah tentu perlu menjadikan sekolah sebagai sebuah tempat untuk menghasilkan pengalaman baharu menerusi proses pembelajaran dan pengajaran. Namun, untuk menentukan sesebuah pengalaman yang diperolehi bersifat mendidik kepada pelakunya, dua prinsip yang telah digariskan sebelum ini perlu diteliti iaitu 'berterusan' dan 'interaksi'. Menerusi prinsip ini, murid bukan hadir ke sekolah dengan 'sifar' pengalaman tetapi hadir dengan pelbagai pengalaman yang diperolehi di rumah dan seterusnya akan mengembangkan pengalaman tersebut secara berterusan menerusi interaksi dengan persekitarannya di sekolah. Dengan kata lain, pembelajaran sebagai satu proses yang melahirkan satu perubahan ilmu, kemahiran, kepercayaan, sikap, nilai dan perkara-perkara berkaitan yang terhasil daripada pengalaman. Sekaligus menggambarkan penghayatan pembelajaran sepanjang hayat menjadi aspirasi utama dalam memahami peranan sekolah yang melihat sekolah bukan sebagai sebuah tempat untuk murid membuat persediaan untuk terus hidup tetapi merupakan tempat bagi murid untuk hidup dalam masyarakat sebenarnya yang lebih kecil daripada masyarakat di luar sekolah.

Realiti di Malaysia, perlaksanaan pembelajaran sepanjang hayat menjadi unsur penting dalam cara hidup setiap warganya dengan menyediakan peluang pendidikan kepada semua rakyat. Peluang tersebut melibatkan pendidikan kebangsaan yang terdiri daripada pendidikan prasekolah, pendidikan rendah, pendidikan menengah, pendidikan lepas menengah dan kemudiaan diikuti dengan pendidikan tinggi. Dalam masa yang sama, terdapat juga tiga jenis sekolah dalam Sistem Pendidikan Malaysia ialah sekolah kerajaan, sekolah bantuan kerajaan dan sekolah swasta. Dua kategori sekolah kerajaan dan bantuan kerajaan iaitu peringkat sekolah rendah sekolah kebangsaan dan sekolah jenis kebangsaan turut diwujudkan. Di sekolah Menengah pula, terdapat Sekolah Menengah Kebangsaan dan Sekolah Jenis Kebangsaan. Sekolah Menengah Kebangsaan merangkumi beberapa jenis sekolah misalnya Sekolah berasrama penuh (SBPI), Maktab Rendah Sains Mara (MRSM), Sekolah Agama, Sekolah Seni dan Sukan, Sekolah Teknik dan Vokasional, Sekolah kluster dan juga Sekolah Menengah Harian. Kesemua sistem pendidikan ini melibatkan tempoh pembelajaran tidak boleh kurang daripada tempoh minimum pendidikan rendah dan menengah sebagaimana yang termaktub dalam Akta Pendidikan 1961. Berkait dengan hal ini, kerajaan amat menggalakkan ibu bapa ataupun penjaga di Malaysia yang terdiri daripada berbilang kaum agar menghantar anak-anak ke Sekolah Kebangsaan. Galakan tersebut bertujuan untuk mewujudkan proses sosialisasi dan persekitaran pembelajaran yang harmoni dalam kalangan murid. Namun, dilema yang menghambat golongan tertentu apabila, kerajaan masih lagi mengekalkan sistem persekolahan vernakular sama ada vernakular Melayu, Cina dan Tamil. Terkini, pembelajaran sepanjang hayat turut dapat dilihat menerusi pendidikan kanak-kanak bukan warganegara dan gelandangan yang diberi peluang untuk mendapat pendidikan asas diperingkat sekolah rendah. 
Begitu juga dengan perlaksanaan lebih ramai murid dalam kalangan isi rumah berpendapatan rendah (B40) diberikan keutamaan untuk memasuki Maktab Rendah Sains MARA (MRSM) dan Sekolah Berasrama Penuh (SBP) di bawah kelolaan kementerian itu.

Dari sudut pandangan Islam, keperluan pembelajaran sepanjang hayat telah menjadi aspirasi utama dalam pendidikan Islam. Buktinya terdapat 791 kali kata 'ilm disebut dalam al-Quran, yang merupakan perkataan keempat yang tertingi selepas perkataan Allah, iman dan rabb. Malah jika diteliti wahyu awal yang diterima oleh Rasulullah mempunyai hubungan dengan ilmu dan kepentingan membaca. Penjelasan ini menggambarkan umat Islam wajib mencari, meneroka, membina dan mengaplikasi ilmu dalam kehidupan. Kehidupan tanpa ilmu adalah kehidupan yang tidak sempurna. Dalam Islam, menjadi tanggungjawab umatnya melengkapkan diri dengan dua bentuk ilmu asas iaitu ilmu fardhu ain dan fardu kifayah.

\section{Bingkai 2}

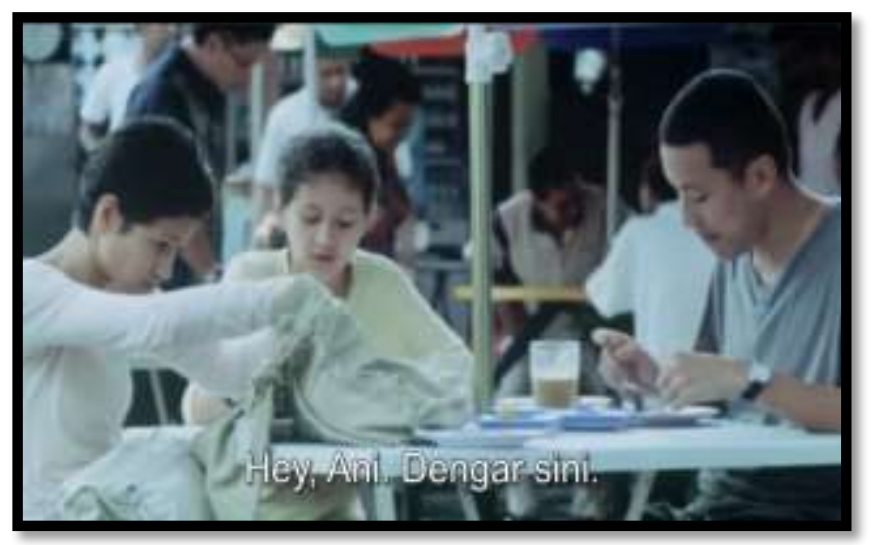

Gambaran tentang pembelajaran sepanjang hayat diperjelaskan lagi dalam bingkai 2. Bingkai ini memaparkan al-Quran sedang dibincangkan di khalayak kedai mamak oleh Rohana, Rohani dan Brian. Perbincangan tersebut melibatkan beberapa isu berkaitan agama dan dilakukan sambil menunggu Brian menyudahkan makanannya. Mise en scene bingkai ini memaparkan firasat Yasmin berkenaan amalan membaca dan mengkaji al-Quran dalam diri individu yang ingin mencari bukan hanya terhenti di masjid, sekolah, universiti, kolej dan institusi. Tetapi boleh juga berlangsung tanpa mengira masa dan tempat. Malah bukan itu sahaja amalan membaca dan mengkaji al-Quran turut boleh dibahaskan di antara orang Islam dengan bukan Islam, lelaki ataupun perempuan, menggunakan bahasa yang mudah difahami oleh individu yang sedang mendekati ajaran al-Quran dan pelbagai lagi cara lain yang akhirnya dapat menambah pengetahuan atau kemahiran diri. Tanpa disedari Yasmin menyarankan sifat ingin tahu terhadap ajaran dalam al-Quran akan menjadikan seseorang individu itu berfikiran kritikal, kreatif, berkeyakinan tinggi dan berusaha untuk mempamerkan minat dan keghairahan membahaskan polemik-polemik agama berikutan kesedaran mereka untuk menjalani kehidupan menurut paksi Islam.

Firasat Yasmin yang melihat amalan watak-watak dalam bingkai ini menjadikan pengalaman al-Quran dibaca dan dikaji tanpa mengira masa dan tempat selari dengan pemikiran Dewey. Pandangan yang melihat pendidikan tidak hanya terhenti pada tahap-tahap tertentu tetapi berlangsung secara berterusan sepanjang kehidupan manusia. Perubahan perlu dilakukan oleh murid dalam usaha untuk memperolehi ilmu seiring dengan perubahan persekitaran yang 
mengalami perubahan. Malah, turut seiring dengan pandangan Dewey yang menegaskan tugas sekolah bukan untuk merubah masyarakat tetapi lebih bertujuan untuk mengenalkan murid-murid kepada masyarakat yang sebenarnya berubah. Jesteru itu, sekolah dilihat perlu memainkan peranan untuk menyediakan situasi yang membolehkan kesinambungan pendidikan meskipun setelah berakhirnya persekolahan hasil. Sekaligus sekolah perlu menyediakan produk-produk manusia yang mempunyai pengalaman hidup yang sentiasa berkembang dalam masyarakat dengan menghasilkan produk terbaik yang terdiri daripada murid-murid yang mampu merealisasikan pembelajaran sepanjang hayatnya.

Realiti di Malaysia, kerajaan telah membina peluang-peluang kepada setiap rakyat untuk mendapatkan ilmu pengetahuan dan kemahiran selepas tamat alam persekolahan selepas sebelas tahun atau tiga belas tahun berada di alam persekolahan. Hal ini kerana, tidak semua lepasan sekolah berpeluang melanjutkan pelajaran dalam bidang akademik, maka mereka inilah yang perlu berpeluang mengikuti bidang-bidang kemahiran yang menjuruskan kepada bidang pekerjaan. Jesteru itu, pembelajaran sepanjang hayat (PSH) perlu menjadi amalan hidup setiap rakyat Malaysia yang dahagakan ilmu dan berusaha meningkatkan kemahiran dan kemajuan diri bagi mencapai apa jua matlamat dan objektif mereka tanpa mengira di mana mereka berada, dalam apa-apa jua keadaan atau situasi, umur dan latar belakang mereka. Situasi ini selari dengan persediaan Malaysia dalam menghadapai cabaran fenomena globalisasi yang melanda dunia. Cabaran yang mendorong berlakunya anjakan paradigma yang amat ketara di Malaysia dalam konteks untuk mencari makna terhadap kualiti pendidikan dan juga kurikulum yang ditawarkan. Hal ini kerana, Malaysia merupakan antara negara yang sedang meningkatkan daya saing dan meningkatkan kualiti pendidikan bertaraf dunia. Walau bagaimanapun, tidak dapat dinafikan dalam usaha melebarkan konsep pembelajaran sepanjang hayat, masih ada lagi masyarakat Malaysia pandai membaca, pandai menulis dan pandai mengira selalu dilihat kurang berinsiatif dan proaktif dalam meluaskan ilmu pengetahuan mereka. Kemungkinan ia berpunca daripada sikap mudah berpuas hati dengan ilmu yang dimiliki. Malah berkemungkinan kerana mereka kurang kesedaran untuk berkongsi ilmu dengan masyarakat sekeliling. Sedangkan jika diteliti, sesuatu perubahan dalam kehidupan merupakan hasil dari pemerolehan dan perkembangan ilmu pengetahuan kerana manusia sepatutnya tidak akan pernah berhenti untuk membaca dan mengkaji sesuatu ilmu ataupun kemahiran yang diperlukan.

Namun, sedikit teguran perlu disampaikan kepada golongan yang menyahut seruan pembelajaran sepanjang hayat dengan berinisiatif untuk mencari pengalaman memahami al-Quran. Mereka ini perlu memahami perbezaan di antara mentafsir dengan mentadabur ayat-ayat al-Quran. Bagi yang keliru dengan perbezaan ini, tidak akan melihat usaha untuk mentafsir al-Quran pada hari ini bukan seperti yang dilakukan oleh Rasulullah, para sahabat yang hidup sezaman dengan baginda dan murid sahabat yang memperolehi sumber asli iaitu Rasulullah. Pentafsiran pada hari ini sebenarnya lebih kepada membaca dan memahami tafsir al-Quran daripada kitab tafsir muktabar berdasarkan riwayat sahih yang boleh dipertanggungjawabkan kebenarannya. Meskipun, usaha tersebut masih lagi memerlukan seseorang itu perlu cukup ilmu seperti ilmu bahasa Arab, ilmu tafsir, ilmu usul fiqh, nasikh mansukh dan lain-lain lagi yang membawa kepada keupayaan menjelaskan maksud ayat Allah SWT di dalam al-Quran. Tidak seperti mentadabbur iaitu mengambil pelajaran dan penghayatan daripada terjemahan al-Quran dengan mengkiaskan pengajaran itu terhadap kehidupan manusia secara peribadi atau masyarakat. Mentadabbur boleh dilakukan oleh sesiapa sahaja tetapi tidak akan terhasil dengan baik melainkan selepas mengetahui tafsirannya kerana pengetahuan yang benar daripada tafsir akan memberi kesan kepada tadabburnya. Misalnya kewujudan blog seperti "letsreadthequran" yang bermisikan "pendemokrasian al-Quran" dengan menganjurkan kempen kesedaran membaca dan memahami al-Quran secara global. Meskipun ia 
merupakan suatu usaha yang positif tetapi sebaliknya akan berlaku jika perbezaan di antara mentafsir dan mentadabbur al-Quran diketepikan. Begitu juga jika pengkajian al-Quran dilihat dari sudut yang sempit akan membawa kemunculan golongan radikal agama seperti militan Daesh.

Secara ringkasnya, setelah melakukan penelitian dan analisis secara terperinci, penulis mendapati bahawa Dewey merupakan tokoh pemikir falsafah pragmatisme dan tokoh pendidik yang tersohor dengan pengalaman sebagai asas pendidikan. Pengalaman biasa dalam dunia sehari-harian ialah satu-satunya realiti yang sentiasa ada pada manusia dan yang diperlukan adakalanya bersifat pasif ataupun aktif. Bagi menentukan sesebuah pengalaman itu mendidik seseorang, dua prinsip perlu dijadikan sebagai panduan iaitu kesinambungan dan interaksi seorang individu dengan persekitaranya. Kedua-dua prinsip ini tidak boleh dipisahkan. Malah, dengan prinsip pengalaman ini, Dewey telah memperkenalkan pembelajaran sepanjang hayat. Pembelajaran sepanjang hayat iaitu ialah satu proses berterusan secara formal dan tidak formal yang berlaku dalam lingkungan corak kehidupan yang melahirkan sebuah masyarakat yang berilmu pengetahuan. Dalam makalah ini juga, penulis melihat pembelajaran sepanjang hayat yang disarankan oleh Dewey menerusi dua bingkai terpilih daripada naskah Muallaf. Bingkai pertama menjelaskan pengalaman yang diperolehi oleh murid dari perbezaan dan persamaan yang wujud dalam masyarat majmuk merupakan lanjutan daripada pengalaman yang bermula dari rumah lagi. Proses menghasilkan pengalaman tersebut kemudiaannya diteruskan di alam persekolahan. Bingkai kedua pula memaparkan pengalaman yang diperolehi di alam persekolahan perlu digunakan untuk menghasilkan pengalaman baru di luar waktu persekolahan ataupun selepas zaman persekolahan. Maka untuk menempuhi alam tersebut, pihak sekolah perlu menghasilkan produk terbaik yang membolehkan semua murid meneruskan penghasilan pengalaman baharu menerusi pembelajaran sepanjang hayatnya. Semua penjelasan ini telah diterjemahkan oleh Yasmin dengan cara berhikmah menerusi filem Muallaf 2008.

\section{References}

Abd Munir Mohamed Noh. 2010. Falsafah Pendidikan Menurut Ibn Khaldun dan John Dewey : Kajian Perbandingan. Disertasi Usuluddin. Jabatan Akidah dan Pemikiran Islam, Akademi Pengajian Islam, Universiti Malaya.

Anastasia Jessica Adinda S. 2015. Menelusuri Pragmatisme Pengantar pada Pemikiran Pragmatisme dari Peirce Hingga Habermes. Surabaya: Pt Kanisius.

Boisvert, R. D. 1995. John Dewey: Rethinking our Time. Albany: State University of New York Press.

Dewey, J. 1920. The School and Society. Chicago: University of Chicago Press.

Dewey, J. 1938. Experience and Education. New York: Kappa Delta Pi.

Dewey, J. 1956. The Development of American Pragmatism. In. D. Runes. Living Schools of Philosophy. Amers, Iowa: Littlefield Adams and Co.

Dewey, J. 1958. Experience and Nature. Revised edition (January 1, 2000). United States: Dover Publications.

Dewey, J. 1964. Democracy and Education: An Introduction to the Philosophy of Education. New York: The Macmillan Company.

Field, R. 2007. The Internet Encyclopedia of Philosophy John Dewey 1859-1952. Maryville: Northwest Missouri State University.

Gibson, G. W. 2016. Experience, Education and Subjectivity: A Comparison of John Dewey's and Maurice Merleau-Ponty's Conceptions of Experience and Their Implications for Education. Tesis Sarjana. Queen's University Kingston: Ontario, Canada.

Gutek, Gerald L. 1988. Philosophical and Ideological Perspectives on Education. New Jersey: PrenticeHall Inc. 
http://ms.wikipedia.org/wiki/Muallaf (film) [16 January 2018]

Joanna, S. Hall. 1996. John Dewey and pragmatism in the primary school: a thing of the past?. Journal Curriculum Studies 4(1):5-23.

Keitges, Mark. 2015. Expanding global learning through case experiences: technological ruminations on Dewey's experience and education University of Illinois at Urbana. Champaign. The Journal of School \& Society 2:1.

Maddux, H. C \& Donnett, D. 2015. John Dewey's pragmatism: implications for reflection in servicelearning. Michigan Journal of Community Service Learning 21(2): 64-73.

Margolis, Joseph. 2000. Introduction: Pragmatism, retrospective, and prospective. pp. 1-10. In. Shook, John R. \& Margolis, Joseph (eds.). A Companion to Pragmatism. Malden, MA: Blackwell Publishing.

Mohamed Nor Che'Nor. 1990. Asas-asas Pendidikan satu Pengenalan. Selangor: Flo Enterprise Sdn. Bhd.

Muallaf. 2008. Filem Cereka. Kuala Lumpur: MHZ Film Sdn. Bhd.

Musa bin Daia. 1973. Sejarah Perkembangan Pendidikan dan Persekolahan. Kota Bharu: Pustaka Aman Press.

Nagendralingan Ratnavadivel. 2007. Pendidikan Sebagai Wahana Untuk Pembagunan Modal Insan: Satu Perbincangan dari Perspektif Swami Vivekananda, Rabindranath Tagore, John Dewey dan Paulo Freire. In. Mohammad Alinor Abdul Kadir, Mohd Nasir Mohd Tap, Nafrulniza Abdul Manap, Khalidah Salekan, Zamri Bali, dan Amin Mohammad Husni Tamrin al-Jufri (eds.). Pasca Sidang Seminar Pendidikan Tinggi Islam I-V, pp. 129-169. Selangor: Kolej Daral-Hikmah.

Omar M. Khasawneh. Ruba M. Miqdadi \& Abdulhakeem Y. Hijazi. 2014. Implementing pragmatism and John Deweys educational philosophy in Jordanian public schools. Journal of International Education Research - First Quarter 10(1):37-54.

Ormerod, Richard. 2006. The History and Ideas of Pragmatism. Journal of the Operational Res earch Society. 57(8): 892-909.

Peterson, A.D.C. 1987. Pendidikan Seratus Tahun. Trans. Kuala Lumpur: Dewan Bahasa dan Pustaka.

Scheffler, I. 1974. 1986. Four Pragmatists. A Critical Introduction to Peirce, James, Mead, and Dewey. London: Routledge \& Paul.

Sharifah Alwiah Alsagoff. 1984. Falsafah Pendidikan. Selangor: Heinemann Educational Books (Asia) Ltd.

Stroh, Guy W. 1968. American Philosophy from Edwards to Dewey. Princeton: Van Nostrand.

Talisse, Robert B. 2000. On Dewey the Reconstruction of Philosophy. New York: The City University of New York.

Thayer, H. S. 1981. Meaning and Action: A Critical History of Pragmatism. Indianapolis: Hackett Publishing Company.

Theobald, P. 2009. Education Now: How Re-thinking America's Past Can Change Its Future. Colorado: Paradigm. 